\title{
Internet chemotherapy information: impact on patients and health professionals
}

\author{
E Davies*, and K-W Yeoh ${ }^{2}$ \\ 'Department of Oncology/Haematology, Northampton General Hospital NHS Trust, Cliftonville, Northampton, NNI 5BD, UK; \\ ${ }^{2}$ Department of Clinical Oncology, The Churchill Hospital, Oxford Radcliffe Hospitals NHS Trust, Old Road, Oxford OX3 7LJ, UK
}

BACKGROUND: Reliable information can improve patients' knowledge of chemotherapy. As internet chemotherapy information (ICl) is increasingly viewed as a valuable patient education tool, we investigated the impact of $\mathrm{ICl}$ on patient care and analysed health professionals' (HPs') attitudes towards $\mathrm{ICl}$.

METHODS: The following questionnaires were distributed: (I) self-administered questionnaire randomly given to 26 I patients receiving chemotherapy (80\% returned); and (2) separate questionnaire given to $58 \mathrm{HPs}$ at the same UK Oncology Centre (83\% returned). RESULTS: Just over half of the patient respondents accessed the internet regularly. They were younger, with higher incomes and qualifications. Key search topics included chemotherapy modes of action, symptom management and treatment success, and most considered ICl useful. More than half wanted to discuss ICl with HPs but most did not get the opportunity. Although the majority of $\mathrm{HP}$ respondents supported the need for patients to retrieve $\mathrm{ICl}$, most questioned the accuracy of $\mathrm{ICl}$ and did not routinely recommend its use.

CONCLUSION: This study has shown that $\mathrm{ICl}$ is generally perceived by patients to be a valuable information resource. Given the potential impact of $\mathrm{ICl}$, the following should be addressed in future studies: (I) inequalities in accessing ICl; (2) maintaining the quality of $\mathrm{ICl}$ (with clear guidance on recommended websites); (3) bridging the gap between the perception of ICl by patients and HPs; (4) integration of $\mathrm{ICl}$ with traditional consultation models.

British Journal of Cancer (2012) 1 06, 65I-657. doi: I0.1038/bjc.20II.60I www.bjcancer.com

Published online 19 January 2012

(C) 2012 Cancer Research UK

Keywords: internet; chemotherapy; education of patients; physicians; nurses; health personnel

Patients with cancer primarily obtain information about their condition and treatment from health professionals (HPs). As patient concerns may not always be met by HPs, it is not uncommon for patients to seek information that will improve their understanding of their disease and treatment from other sources, including the internet (Fallowfield et al, 1994; Meredith et al, 1996; Jenkins et al, 2001; Mayer et al, 2007).

Access to the internet varies between regions and countries. At the time of this study, approximately $76 \%$ of the UK population accessed the internet, with millions among them searching daily for health-related information (Internet Access from the Office of National Statistics, 2011). It has been shown that cancer patients seek online information disproportionately more frequently than other health-related searchers (Chen and Siu, 2001; Pautler et al, 2001; Fogel et al, 2002; Smith et al, 2003; Basch et al, 2004; Newnham et al, 2006; van de Poll-Franse and van Eenbergen, 2008). With cancer information on the internet being viewed as an increasingly important patient education tool, there may be potential issues with the credibility and quality of websites and access thereto. In the same vein, HPs' attitude towards cancer information on the internet is increasingly relevant in determining

*Correspondence: E Davies; E-mail: elaine.davies@ngh.nhs.uk Received 2 September 2011; revised 28 November 2011 ; accepted 16 December 2011; published online 19 January 2012 how internet information can be integrated within traditional consultation models, if at all.

Although much work has been based on internet and cancer in general (Biermann et al, 1999; Chen and Siu, 2001; Eysenbach, 2003; Helft et al, 2003; Helft et al, 2005; Newnham et al, 2005; Newnham et al, 2006; van de Poll-Franse and van Eenbergen, 2008), there have been no studies examining the experience by patients on chemotherapy and by their respective HPs with internet chemotherapy information (ICI). Consequently, the effect of ICI on patient care and outcomes remains largely unknown on this group of patients. The perception of HPs towards ICI is also unknown. This group of patients will potentially be more at risk of experiencing toxicities from cancer treatment and should also have the opportunity for regular interaction with HPs during clinical reviews before ongoing cycles of chemotherapy.

This study investigated the proportion and characteristics of patients who specifically sought ICI while receiving chemotherapy treatment for a variety of tumour types at a cancer centre in the UK. The main aims of the study were to investigate the following: (1) whether ICI was considered beneficial or detrimental by cancer patients and their HPs; (2) the attitudes of HPs to patients who received ICI; and (3) HPs' awareness of their patients' needs for information outside the clinical setting, including ICI. The outcomes of this study will be considered in order to determine how HPs may utilise ICI as a meaningful tool to address patient educational needs and for future studies. 
This paper should also prove to be a useful case study or illustration for other cancer centres.

\section{SUBJECTS AND METHODS}

\section{Patients and HPs}

This study focused on a group of patients who commenced chemotherapy treatment during a 6-month period and the HP team who were directly involved in their care at the Northamptonshire Oncology Centre (the 'Centre'), which is based in a 650 bed district general hospital.

Patients were selected by simple random sampling, whereby every third patient attending the day case chemotherapy centre for the second cycle of chemotherapy was given a self-administered questionnaire, during a 6-month period. The cancer types shown in Table 1 represent the most common cancers seen at our centre. Patient inclusion criteria were as follows: (1) age $\geqslant 18$ years; (2) able to speak and understand English; and (3) undergoing chemotherapy with a cancer diagnosis, at any stage. Informed consent was obtained from each patient.

The questionnaires were designed based on the previous studies in North America, Canada and Australia, which had looked at general internet cancer related information (Chen and Siu, 2001;
Basch et al, 2004; Helft et al, 2005; Newnham et al, 2005, 2006). Modifications were made with additional questions added to meet the aims of this study. As none of the questionnaires from any of the previous studies had been formally validated, an initial validation pilot was conducted in accordance with current recommendations (Sudman and Bradburn, 1982; Oppenheim, 1992; Peterson, 2000; McColl et al, 2001). After refinement, the final version was submitted and approved by the institutional Patient Advisory Liaison Services (PALS) and Research and Development Department. The patient questionnaire contained 52 questions, split into six manageable sections. The self-administered questionnaire for HPs contained 28 questions, split into five sections. Questions were predominantly closed and required either simple dichotomous, multiple choice ordinal, or scaled nominal categorical responses.

\section{Statistical analysis}

Statistical analyses were performed using SPSS/Windows version 15.0.1 software (SPSS Inc., Chicago, IL, USA) statistical software. Univariate analyses, Pearson $\chi^{2}$ test, examined group differences and significant association for patient demographic and characteristic variables, whereas $t$-tests compared means and association of continuous variables. All $P$-values (significance) were two-sided and considered significant if $<0.05$.

Table I Patient socio-demographics characteristics

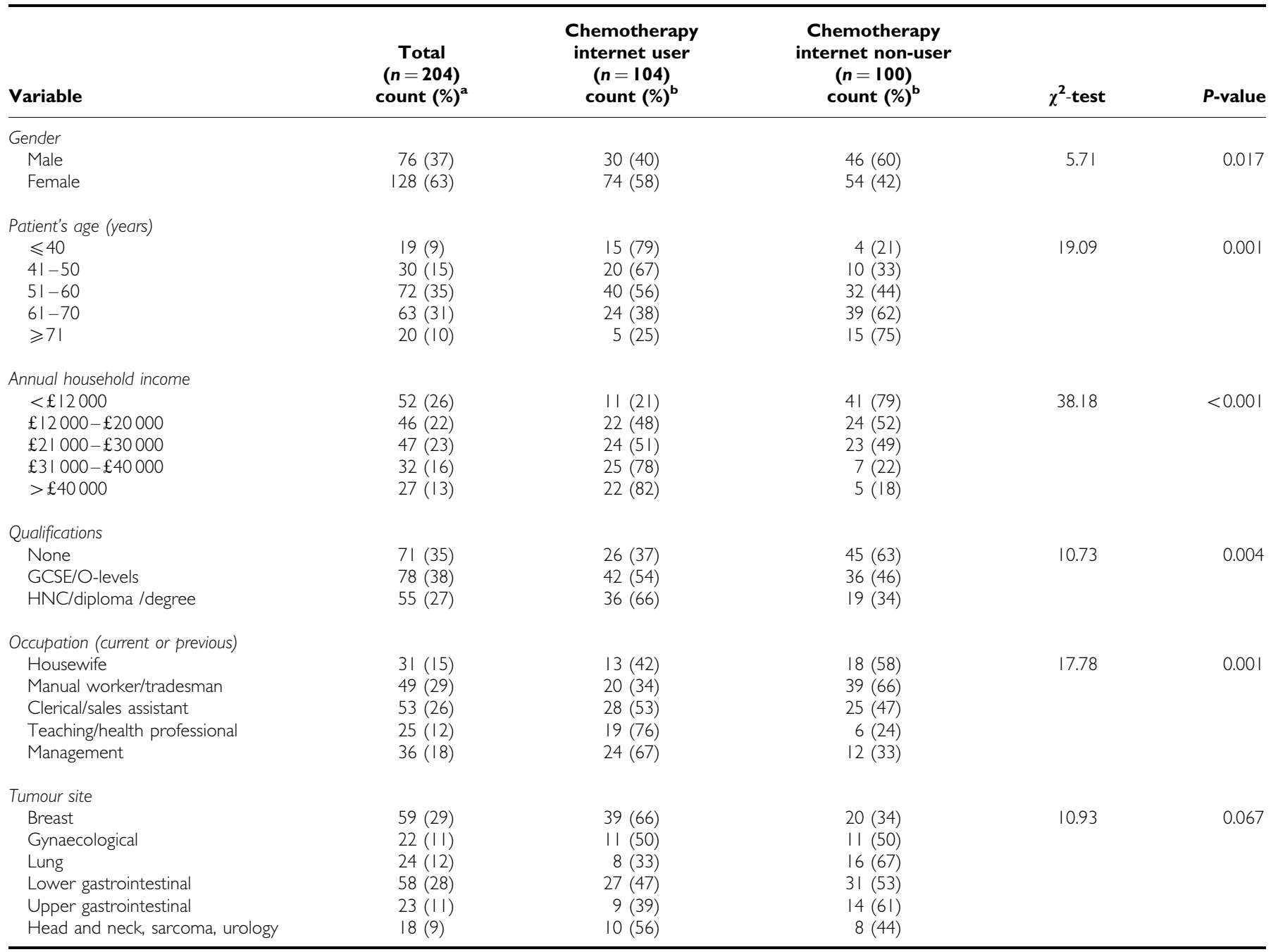

a\% Within the total. ${ }^{\text {bo }}$ Within the categorical variable. 


\section{RESULTS}

\section{Patient questionnaires}

In all, $209(80 \%)$ of the 261 eligible patients who received the questionnaires returned them. Five of these questionnaires were incomplete and excluded. Therefore, 204 questionnaires were included in the final analysis. In all, 156 (76\%) of the respondents had received online information, of which 104 had specifically received ICI. Of these 104, 73 (70\%) conducted online searches themselves and $31(30 \%)$ received the ICI from carers.

Socio-demographic and clinical characteristics for the patient respondents are described in Table 1 . The mean age for respondents who used the internet was 54 years $(S D=11)$ and 60 years $(S D=9.5)$ for non-users. The purpose of treatment did not significantly affect the frequency of online searching; ICI was received by $52 \%$ of patients undergoing adjuvant or radical chemotherapy compared with $48 \%$ of those with palliative intent.

The results show an association between computer access and receipt of ICI; $88 \%$ of the 104 respondents who obtained ICI had a home computer whereas the remainder used computers at work or libraries. A total of 79\% accessed ICI after discussing chemotherapy with their oncologist who gave them the printed patient information leaflets from macmillan.org.uk. The macmillan.org.uk website was accessed by $48 \%$ of the 104 respondents. Other websites that were commonly cited included cancerresearch.org.uk, cancerhelp. org.uk, breastcancercare.org.uk and beatingbowelcancer.org.uk. No other websites were identified by the 104 respondents. Figure 1 illustrates how these respondents rated the importance of ICI, pre-printed hospital information, the media and information obtained from HPs. Telephone help lines, patient support groups, internet chat rooms and other patients with cancer were all considered much less important information resources. Table 2 sets out the impact of ICI on such respondents (including whether they felt anxious, reassured or whether they required further clarification from HPs after reviewing ICI) and identifies key topics that were relevant to their searches (including side effects and how to manage them as well as success rates of chemotherapy).
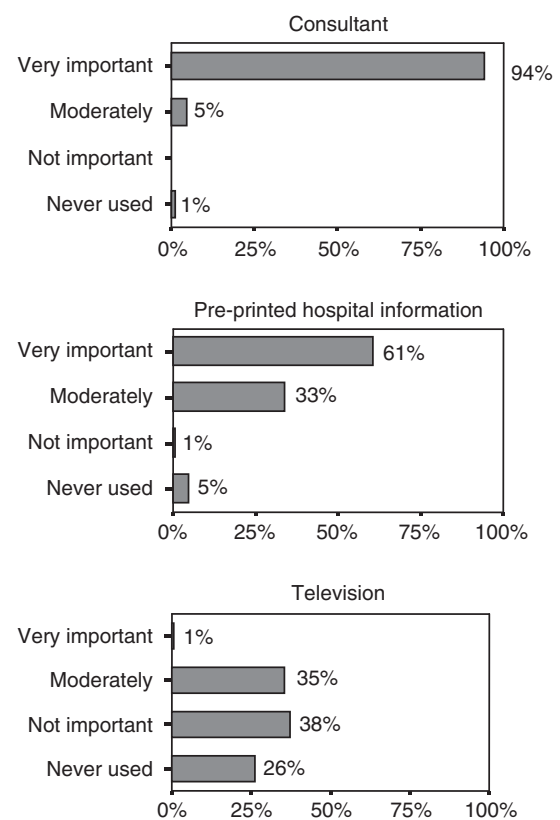

Figure I Patient ratings of cancer information resources.

\section{HP questionnaires}

Questionnaires were given to all 58 HPs at the Centre, of which 47 $(81 \%)$ were returned completed. In all, $25(53 \%)$ of the HPs were consultant oncologists or specialist registrars and $22(47 \%)$ were specialist oncology nurses. The age of the respondents ranged from 28 to 63 years with a mean age of 43 years $(S D=9.9)$.

All respondents considered that written and verbal patient information supplied by the Centre were essential, whereas $70 \%$ considered the internet an important additional information resource. A total of $77 \%$ of HPs regularly viewed ICI, in order to be informed when patients asked questions and to consider the accuracy of ICI. The HPs' opinions of ICI are described in Table 3. A majority of the 47 respondents considered ICI to be inaccurate at times and potentially harmful to patients (in that ICI can add to patient anxiety and be misinterpreted). The HPs' attitudes towards ICI (including how frequently websites are recommended to patients and ICI content is discussed with them) are shown in Table 4. The HPs' opinions and perceptions of patients receiving ICI are summarised in Table 5.

\section{DISCUSSION}

\section{The role of ICI}

This study raises interesting issues about the evolving role of the internet in the sphere of patient education and healthcare generally. It is undeniable that reliable information can improve patients' understanding of chemotherapy and help to allay common concerns. In this study, almost all patient respondents regarded verbal information from HPs and pre-printed leaflets from hospitals as primary sources of information about cancer and its treatment, mirroring the findings of several earlier studies (Meredith et al, 1996; Chen and Siu, 2001; Eysenbach, 2003; Balmer, 2005; Helft et al, 2005; Newnham et al, 2006; James et al, 2007; Mayer et al, 2007). According to previous studies, additional information sources included discussion with other patients, television, newspapers, and magazines. Telephone helplines and patient support groups were less popular sources of information (James et al, 1999; Basch et al, 2004; Balmer, 2005). As would be
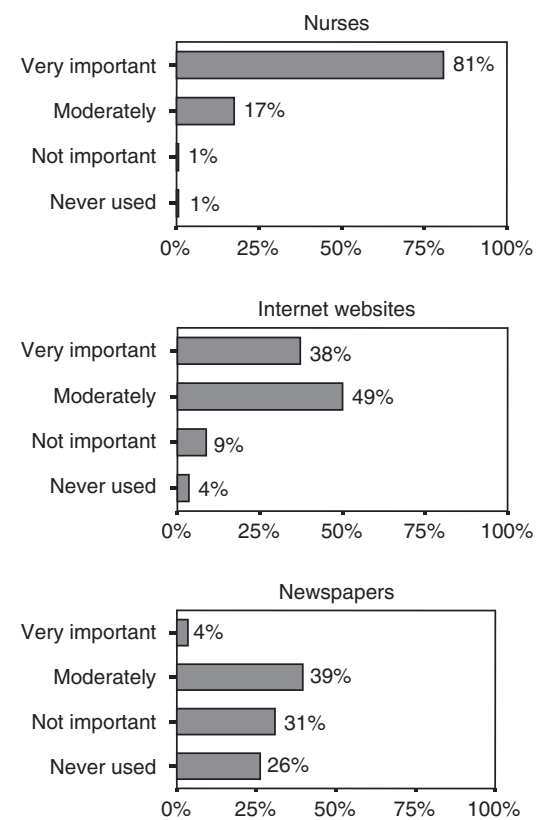
Table 2 Patients key interests and opinions of $\mathrm{ICl}$

\begin{tabular}{|c|c|}
\hline Variable & $\begin{array}{c}\text { Total }(n=104) \\
\text { count }(\%)\end{array}$ \\
\hline \multicolumn{2}{|l|}{ Key interests of patients } \\
\hline List of side effects & $86(83)$ \\
\hline Why side effects occur & $80(77)$ \\
\hline How side effects are managed & $75(72)$ \\
\hline Mode of action of chemotherapy & $88(85)$ \\
\hline How chemotherapy is administered & $72(69)$ \\
\hline Chemotherapy treatment success & $65(63)$ \\
\hline New treatments & $58(56)$ \\
\hline Clinical trials & $36(35)$ \\
\hline Alternative treatments & $28(27)$ \\
\hline \multicolumn{2}{|l|}{ How helpful was internet information } \\
\hline Very helpful & $57(55)$ \\
\hline Moderately helpful & $47(45)$ \\
\hline \multicolumn{2}{|l|}{ Internet answer additional questions } \\
\hline All & $8(8)$ \\
\hline Some & $72(69)$ \\
\hline None & $24(23)$ \\
\hline \multicolumn{2}{|l|}{ Internet clarified hospital information } \\
\hline Yes & $63(61)$ \\
\hline No & $41(39)$ \\
\hline \multicolumn{2}{|l|}{ Internet information reassured patient } \\
\hline Yes & $57(55)$ \\
\hline No & $47(45)$ \\
\hline \multicolumn{2}{|l|}{ Patient felt confused } \\
\hline Yes & $16(15)$ \\
\hline No & $88(85)$ \\
\hline \multicolumn{2}{|l|}{ Patient felt anxious } \\
\hline Yes & II (II) \\
\hline No & $93(89)$ \\
\hline \multicolumn{2}{|l|}{ Patient coped better with treatment } \\
\hline Yes & $55(53)$ \\
\hline No & $49(47)$ \\
\hline \multicolumn{2}{|l|}{ Created realistic hope or expectations } \\
\hline Yes & $64(62)$ \\
\hline No & $40(38)$ \\
\hline \multicolumn{2}{|l|}{ Knew which websites were trustworthy } \\
\hline Yes & $48(46)$ \\
\hline No & $56(54)$ \\
\hline \multicolumn{2}{|l|}{ Required guidance to websites } \\
\hline Yes & $61(59)$ \\
\hline No & $43(4 I)$ \\
\hline \multicolumn{2}{|l|}{ Wanted to discuss with health professional } \\
\hline Yes & $64(61)$ \\
\hline No & $40(39)$ \\
\hline \multicolumn{2}{|c|}{ Opportunity to discuss with health professional } \\
\hline Yes & $63(61)$ \\
\hline No & $41(39)$ \\
\hline
\end{tabular}

Abbreviation: $\mathrm{ICl}$, internet chemotherapy information.

expected with the increased availability of the internet in recent years, the proportion of patients receiving internet information has increased significantly; one would expect this trend to continue. However, given the pressures on health systems worldwide, visits to HPs are often subject to time constraints and patients may not always have the opportunity to raise or discuss all the issues that
Table 3 Health professionals' opinions of $\mathrm{ICl}$

\begin{tabular}{|c|c|}
\hline Variable & $\begin{array}{c}\text { Total }(n=47) \\
\text { count }(\%)\end{array}$ \\
\hline \multicolumn{2}{|l|}{ How often is $\mathrm{ICl}$ accurate } \\
\hline Sometimes & $40(85)$ \\
\hline Rarely & 7 (15) \\
\hline \multicolumn{2}{|l|}{ Can the internet cause harm to the patient } \\
\hline Yes & $41(87)$ \\
\hline No & $6(13)$ \\
\hline \multicolumn{2}{|l|}{ Mechanisms of harm to patient } \\
\hline Misinterpretation of internet information & $39(83)^{\mathrm{a}}$ \\
\hline Create unrealistic patient expectations & $36(77)^{a}$ \\
\hline Causes anxiety, distress or confusion & $37(79)^{a}$ \\
\hline Unable to assess quality/reliability & $35(75)^{a}$ \\
\hline Information is inaccurate or poor quality & $28(60)^{a}$ \\
\hline Unproven/alternative treatment requested & $33(70)^{\mathrm{a}}$ \\
\hline Treatment is unavailable due to cost & $24(5 \mathrm{I})^{\mathrm{a}}$ \\
\hline
\end{tabular}

Table 4 Health professionals' recommendation of websites and discussion of $\mathrm{ICl}$ with patients

\begin{tabular}{lc}
\hline Variable & $\begin{array}{c}\text { Total (n= 47) } \\
\text { count (\%) }\end{array}$ \\
\hline HPs' estimation of patients who received ICI $^{\prime}$ & $27(57)$ \\
$25 \%$ of patients & $16(34)$ \\
$50 \%$ of patients & $4(9)$ \\
$75 \%$ of patients & \\
& \\
Do HPs routinely recommend websites to patients & $9(19)$ \\
Sometimes & $38(81)$ \\
Rarely & \\
If patient requests ICI, are websites recommended & $36(77)$ \\
Often & $7(15)$ \\
Sometimes & $4(8)$ \\
Rarely & \\
HPs' estimation of patients who want to discuss ICI & \\
$25 \%$ of patients & $32(68)$ \\
$50 \%$ of patients & $12(26)$ \\
$75 \%$ of patients & $3(6)$ \\
How often do HPs discuss ICI & \\
Always & $17(32)$ \\
Most of the time & \\
Rametimes & \\
\hline
\end{tabular}

Abbreviations: HPs, health professionals; ICl, internet chemotherapy information.

concern them during the consultation with the HP. In a field as vast, technically challenging and rapidly evolving as oncology, the role of supplementary information outside the traditional consultation setting can be significant, particularly if such information is accessible and suitably targeted at a lay audience. Appropriate written information, including ICI, is useful as it allows the patient to absorb material information at their own pace, refresh key issues and hopefully clarify some of their concerns (Fallowfield et al, 1994; Meredith et al, 1996; Jenkins et al, 2001; Mayer et al, 2007). It is not surprising that the majority of patient respondents who received ICI considered it to be an important resource. 
Table 5 Health professionals' opinions and perceptions of patients receiving $\mathrm{ICl}$

\begin{tabular}{lr}
\hline Variable & $\begin{array}{r}\text { Total }(\mathbf{n}=\mathbf{4 7}) \\
\text { count (\%) }\end{array}$ \\
\hline Attitude towards patients who searched for ICI & \\
Supportive & $32(68)$ \\
Neutral & $15(32)$ \\
Do HPs feel challenged when patients discuss ICI & \\
Sometimes & $5(10)$ \\
Rarely & $22(47)$ \\
Never & $20(43)$ \\
Why do patients search for ICI & \\
Look for complimentary/alternative treatments & \\
Seek reassurance/understanding of treatment & $44(94)^{\mathrm{a}}$ \\
Hope to find a new treatment & $37(79)^{\mathrm{a}}$ \\
Learn about prognosis after chemotherapy & $35(75)^{\mathrm{a}}$ \\
Look for the information on the side effects & $29(62)^{\mathrm{a}}$ \\
Insufficient information supplied by Oncology Center & $23(49)^{\mathrm{a}}$ \\
& $9(19)^{\mathrm{a}}$ \\
How often do patients accurately interpret ICI & \\
Often & $9(19)$ \\
Sometimes & $35(75)$ \\
Rarely & $3(6)$ \\
Are patients who search the internet better informed & \\
Better & $19(40)$ \\
No difference & $28(60)$ \\
Do internet searchers cope better or worse & \\
No difference & $39(83)$ \\
Worse & $8(17)$ \\
\hline
\end{tabular}

Abbreviations: HPs, health professionals; ICl, internet chemotherapy information. ${ }^{\text {a }}$ Total does not add up to total number, as none, or more than one question could be answered in this section.

\section{Access to ICI-addressing inequalities}

As mentioned above, about three quarters of the patient respondents who accessed ICI searched for such information themselves, whereas the remainder received the information from carers. The results of this study are consistent with previous studies of patients with cancer who searched for health-related information and their socio-demographic characteristics (Chen and Siu, 2001; Eysenbach, 2003; Helft et al, 2005; Newnham et al, 2006; Mayer et al, 2007). Patients who received ICI tended to be younger, better educated with higher household incomes. Accordingly, they were more likely to be familiar with and have regularly used the internet. Of the patients who had not sought ICI, a third cited a lack of internet access, half stated that they were not interested in internet information, whereas the remainder were either not aware of chemotherapy websites or were concerned that they would be unduly anxious after receiving ICI. In relation to the latter point, it should be noted that avoiding or limiting information may be a coping mechanism to decrease distress, manage ambiguity and foster hope (Leydon et al, 2000; Mayer et al, 2007).

Given the inevitable and growing influence of internet information, inequalities relating to internet access and patients' internet skills or awareness should perhaps be considered in future health and social policies, in order to ensure that patients across the socio-demographic spectrum have similar, if not equal, opportunities to access appropriate ICI. Improved access and skills relating to the internet cannot, however, be considered in isolation. Future studies and consideration should be given to the following: (1) whether ICI does in fact have a significant and positive impact on patient's well-being; (2) whether the appropriate checks and balances are in place to ensure that patients access ICI that is accurate as opposed to misleading and damaging information; and (3) whether patients and HPs have a consistent understanding of the role of ICI as an educational tool that can be integrated seamlessly into traditional consultation models. Measures may even be introduced to facilitate access to good quality ICI at the cancer centres and other similar settings.

In relation to gender-related inequalities, the proportion of female patients who received ICI was higher than males. This concurs with the results in previous studies where women have been shown to be more active health seekers than men (Fogel et al, 2002; Eysenbach, 2003).

There did not appear to be material inequalities in relation to the kinds of cancers researched online; a broad range of cancers seemed to have been looked into by patient respondents. Although the earlier studies have shown an association between cancer type and level of internet usage (Chen and Siu, 2001; Eysenbach, 2003; Helft et al, 2005; Newnham et al, 2006), the tumour site did not seem to significantly influence whether or not patients received ICI in this particular study.

\section{Patient perceptions of ICI}

The results obtained in this study, particularly in relation to patient perceptions of ICI, can be usefully integrated into future and broader investigations relating to the internet and how it can be meaningfully used to improve the quality of patient care and education, not only in the field of oncology but also in other areas of medicine.

Patient attitudes to ICI were generally positive. Encouragingly, less than a quarter admitted that they were confused by ICI and an even smaller proportion felt anxious having reviewed ICI. This is in contrast with the concerns of the majority of HP respondents who worried about the negative implications of ICI (to be discussed later). Patients frequently fear chemotherapy toxicity, so it was no surprise that the majority searched for ICI relating to side effects, with three quarters wanting to understand the mode of action of chemotherapy, how successfully it controls symptoms and the method of administration. Only half of the patients expressed an interest in new treatments, a third in clinical trials and merely a quarter in alternative treatments. Patients' hopes are often raised when they learn about a new treatment through the media, but only a third considered that the internet had created unrealistic expectations. More than half felt reassured by ICI, believing that they felt more in control of their treatment, more compliant and better able to cope with the adverse effects. For patients who did not seek ICI, the main reasons, as discussed earlier, were either because they were not interested or had no access to ICI. Only a minority felt that they would be unduly anxious after receiving ICI. This does, however, highlight that patients have different coping styles, which need to be tailored for individually (Miller, 1995).

\section{The quality and accuracy of ICI-checks and balances}

Given that patients do value ICI as a useful source of information (and the role of ICI is likely to grow with the advent of the information age), it has become increasingly important to ensure that patients are able to access good quality and accurate information. This consideration applies equally across all aspects of medicine and healthcare. In this regard, the following considerations are crucial: (1) patients must be given some guidance and direction to websites that are accurate, reliable and user-friendly (in that the content must be easily understood by the lay person and not be overwhelming, confusing or misleading); (2) patients must be given the opportunity to clarify any doubts or to raise questions following their review of ICI; and (3) the quality 
of recommended websites must be maintained and be subject to ongoing review and validation by HPs.

(2) is an important consideration and HPs must be live to the fact that patients will become increasingly able to obtain information about cancer outside the consultation and will have follow-on questions and concerns that they may wish to raise with HPs. Patients must also be made to understand the time and other constraints of a consultation and appreciate that ICI can only supplement or complement case-specific advice given by the HP.

In relation to (3), it is reassuring that the vast majority of patient respondents in this study listed peer-reviewed websites such as macmillan.org.uk or cancerresearchuk.org as their source of ICI. Although almost half of the study patients thought they were able to identify which websites they considered to be trustworthy, more than half indicated that they required further guidance from HPs. This is something that should be addressed in future.

\section{HP perceptions of ICI}

Although earlier studies have described HPs' concerns that the internet can be inaccurate, distressing or overrated by patients, it was encouraging that most HPs in this study believed that the internet has the potential to increase patients' understanding of the disease and its treatment (Biermann et al, 1999; Chen and Siu, 2001; Helft et al, 2003; Newnham et al, 2005). Although two thirds had a generally supportive attitude, the majority considered that the internet could be detrimental and cause harm to more vulnerable patients. There were concerns that patients may develop unrealistic expectations, become anxious or confused, as a result of their inability to interpret and assess the quality, accuracy and reliability of information. Almost three quarters thought that patients may request unproven treatments, whereas around half feared that a new or alternative treatment may be sought, which was either unavailable due to high costs, or be unsuitable for the patients' condition. Two thirds believed patients were interested in prognosis following chemotherapy but less than half considered their interest in side effects. Most HPs thought that patients search to seek reassurance and a better understanding of chemotherapy, or are hopeful to find a successful treatment for their cancer.

The sharing of ICI with HPs provides an opportunity for the patient to clarify any confusion or misunderstandings. Despite more than half of the patients indicating that they would have liked to discuss their findings, the majority had not been given an opportunity. The HPs not only underestimated the proportion of patients who received internet information, but some appeared unaware of the patients' needs for guidance and opportunities for discussion. Only a small proportion of HPs recommended websites unless specifically requested by patients. It should perhaps be considered important for HPs to determine what information patients are most interested in, how they can offer guidance to credible websites, and to realise that patients may need assistance to accurately interpret the information. Although some found it difficult to allow time, most recognised that this is not a challenge to their authority but an effort by patients to learn more and better understand their disease and chemotherapy treatment. This raises questions as to whether there is a perceived or real need to actively offer patients the opportunity to discuss retrieved information, as discrepancy of information from HPs compared with ICI may raise issues from patients. Discussion of ICI could in fact be an opportunity to strengthen this relationship by clarifying concerns, relieving anxiety and assisting in more complex decision making. In addition to offering guidance to patients, it should be acknowledged that some will prefer not to receive ICI, and they should be reassured that HPs provide all the information required for the treatment.

As the availability of ICI continues to develop, HPs should be involved in its regulation and peer review. This will ensure that information is evidence based and presented in a balanced format suitable to the patients' level of understanding while maintaining homogeneity of websites' standards. A recently developed webbased tool in the UK is the National Cancer Action Team's 'Patient Information Prescription' (Cancer Patient Information Pathways, 2011). This offers a consistent approach to disease and treatment information, enabling HPs to provide standardised peer reviewed information leaflets, and direct patients to quality-reviewed websites according to individual needs. Perhaps the best application of ICI should be for it to be integrated with current traditional consultation models to enhance patient experience and provide additional information in conjunction with that provided by HPs.

In conclusion, although the primary source of chemotherapy information remains that of HPs, this study has shown that ICI is generally perceived by patients to be a valuable information source, which is used to augment information traditionally obtained through HPs. Although HPs had some understandable concerns regarding the possible detrimental effect to patients and their ability to interpret internet information, the majority generally recognised and supported the need for patients to retrieve internet information to improve their understanding of chemotherapy treatment. It has nevertheless revealed discrepancies that exist between HPs perception and patients' needs with regards to ICI seeking behaviour. This emphasises a need for HPs to work more closely with patients in addressing their concerns and directing them to credible websites.

This study has therefore highlighted the need to: (1) improve access to ICI; (2) to reassess current consultation models to address individual needs; (3) to provide guidance and; (4) to maintain quality assurance of accredited chemotherapy websites. It follows that the potential exists to integrate ICI with current traditional consultation models synergistically in order to enhance patient experience.

\section{Conflict of interest}

The authors declare no conflict of interest.

\section{REFERENCES}

Balmer C (2005) The information requirements of people with cancer: where to go after the 'patient information leaflet'. Cancer Nurs 28(1): $36-44$

Basch EM, Thaler HT, Shi W, Yakren S, Schrag D (2004) Use of information resources by patients with cancer and their companions. Cancer 100(11): $2476-2483$

Biermann JS, Golladay GJ, Greenfield ML, Baker LH (1999) Evaluation of cancer information on the internet. Cancer 86(3): $381-390$
Cancer Patient Information Pathways (2011). Available from URL: http:// www.cancerinfo.nhs.uk/cancer-patient-information-pathways (accessed 12 June 2011)

Chen X, Siu LL (2001) Impact of the media and the internet on oncology: survey of cancer patients and oncologists in Canada. J Clin Oncol 19(23): $4291-4297$

Eysenbach G (2003) The Impact of the internet on cancer outcomes. CA Cancer J Clin 53: 356-371 
Fallowfield L, Ford S, Lewis S (1994) No news is not good news: information preferences of patients with cancer. Physio-oncology 4: $197-202$

Fogel J, Albert SM, Schnabel F, Ditkoff BA, Neugut Al (2002) Use of the internet by women with breast cancer. J Med Internet Res 4(2): e9

Helft P, Hlubocky F, Daugherty K (2003) American oncologists' views of internet use by cancer patients: a mail survey of American Society of Clinical Oncology Members. J Clin Oncol 23(5): $942-947$

Helft PR, Eckles RE, Johnson-Calley CS, Daugherty CK (2005) Use of the internet to obtain cancer information among cancer patients at an urban county hospital. J Clin Oncol 23(22): 4954-4962

Internet Access from the Office of National Statistics (2011). Available from URL: http://www.statistics.gov.uk/pdfdir/iahi0809.pdf (accessed 12 June 2011)

James C, James N, Davies D, Harvey P, Tweddle S (1999) Preferences for different sources of information about cancer. Patient Educ Couns 37(3): $273-282$

James N, Daniels H, Rahman R, McConkey C, Derry J, Young A (2007) A study of information seeking by cancer patients and their carers. Clin Oncol ( $R$ Coll Radiol) 19: 356-362

Jenkins V, Fallowfield L, Saul J (2001) Information needs of patients with cancer: results from a large study in UK cancer centres. $\mathrm{Br} J$ Cancer 84: $48-51$

Leydon GM, Boulton M, Moynihan C, Jones A, Mossman J, Boudioni M, McPherson K (2000) Cancer patients' information needs and information seeking behaviour: in depth interview study. Brit Med J 320: $909-913$

Mayer DK, Terrin NC, Kreps GI, Menon U, McCance K, Parsons SK, Mooney KH (2007) Cancer survivors information seeking behaviours: a comparison of survivors who do and do not seek information about cancer. Patient Educ Couns 65(3): $342-350$
McColl E, Jacoby A, Thomas L, Soutter J, Bamford C, Steen N, Thomas R, Harvey E, Garratt A, Bond J (2001) Design and use of questionnaires: a review of best practice applicable to surveys of health service staff and patients. Health Technol Assess 5(31): 1-256

Meredith C, Symonds P, Webster L, Lamont D, Pyper E, Gillis CR, Fallowfield L (1996) Information needs of cancer patients in West Scotland: cross sectional survey of patients' views. Br Med J 313: 724-726

Miller SM (1995) Monitoring versus blunting styles of coping with cancer influence the information patients want and need about their disease. Implications for cancer screening and management. Cancer 76: $167-177$

Newnham GM, Burns WI, Snyder RD, Dowling AJ, Ranieri NF, Gray EL, McLachlan SN (2005) Attitudes of oncology health professionals to information from the internet and other media. Med J Aust 183(4): 197-200

Newnham GM, Burns WI, Snyder RD, Dowling AJ, Ranieri NF, Gray EL, McLachlan SN (2006) Information form the internet: attitudes of Australian oncology patients. Intern Med J 36(11): 718-723

Oppenheim AN (1992) Questionnaire Design, Interviewing and Attitude Measurement. Pinter Publishers: New York and London

Pautler SE, Tan JK, Dugas GR, Pus N, Ferri M, Hardie WR, Chin JL (2001) Use of the internet for self-education by patients with prostate cancer. Urology 57(2): 230-233

Peterson RA (2000) Constructing Effective Questionnaires. Sage Publications: California

Smith RP, Devine P, Jones H, DeNittis A, Whittington R, Metz JM (2003) Internet use by patients with prostate cancer undergoing radiotherapy. Urology 62: 273 - 277

Sudman S, Bradburn NM (1982) Asking Questions: A Practical Guide to Questionnaire Design. Jossey-Bass Publishers: San Francisco

van de Poll-Franse LV, van Eenbergen MC (2008) Internet use by cancer survivors: current use and future wishes. Support Care Cancer 16(10): 1189-1195

This work is published under the standard license to publish agreement. After 12 months the work will become freely available and the license terms will switch to a Creative Commons Attribution-NonCommercial-Share Alike 3.0 Unported License. 